\title{
GENETIC AND BIOCHEMICAL DIVERSITY OF HYPERICUM PERFORATUM L. GROWN IN THE CASPIAN CLIMATE OF IRAN
}

\author{
RAHNAVRD, A. \\ Department of Medicinal Plants, Tonekabon Branch, Islamic Azad University, Tonekabon, Iran \\ Rahnavard_Aptin@yahoo.com \\ (fax:+98-5425-444-422) \\ (Received 10 $0^{\text {th }}$ Sep 2016; accepted $15^{\text {th }}$ Dec 2016)
}

\begin{abstract}
Hypericum perforatum, also known as St John's wort, is an important medicinal plant that produces many secondary metabolites that have anti-viral, anti-bacterial, and anti-depression properties. The most effective drug substance in this plant is hypericin that changed in the various genotypes. To investigate the genetic and biochemical diversity of Hypericum perforatum, samples were collected from different genotypes around the Caspian climate region. A total of 15 genotypes from the Hyrcanian Province in the Caspian climate region were evaluated using 15 randomized amplified primers design (RAPD primers). A total number of 90 bands with the average of bands amplified by each primer was 9band. The number of polymorphic bands per primer ranged from 1 to 13 and the bands were 250 to 3000 bp in size. Based on the results, OPAD-10 primer with 13 bands and OPV10 with 7 bands were used as the maximum and minimum number of amplified fragment, respectively. Molecular marker genotypes showed a high degree of polymorphism. Based on the RAPD results, the genotypes were divided into 4 groups. Most similar genotypes with a coefficient of $75 \%$ were in subgroup $\mathrm{A}_{3}$ (Noshahr and Kelardasht). Variation in hypericin was very significant in the genotypes grown under identical conditions. The highest amount of hypericin was measured in the Kelardasht genotype and the lowest amount in the Roodsar genotype.
\end{abstract}

Keywords: biodiversity, population genetics, St John's wort, RAPD, plant, genotype

\section{Introduction}

The side effects of synthetic drugs have led to the widespread use of medicinal plants and several drugs with plant origin have been recently produced and marketed. Hypericum perforatum, which is part of the family Hypericaceae, is one of the most important plants in the pharmaceutical industry. It is produced by developed countries and can be found as an ingredient in several anti-depressants (Azizi and Omidbaigi, 2002; Tonk et al., 2011). There are about 200 medicinal plants in the Hypericaceae family. The flowers are widely appearing to coincide on June 24th (St. John's birthday) (Bais et al., 2003). Tiny spots on the petals, which can be observed as dark lines in the secretory glands, contain terracotta-colored sap. This is the secondary metabolite that contains a substance called hypericin (Omidbeigy, 2001; Mitch, 1994). Hypericin is one of the most important active substances that nowadays, are an integral part of biologically active substances, are of great interest. They can reduce mutagenic influence, regulating the oxidation process of free radicals (Mairapetyan et al., 2016). In Greek history, Discourse, Polini, and Hippocrates were using hypericin (Weed, 2000). Until about a century ago, for the first time in Germany for industrial products and about three decades ago, it was used in many products marketed in the US and European countries (Peterson et al., 2001; Vardanyan et al., 2014). Since ancient times, this herb has been used to treat wounds, burns, abdominal pain, and bacterial diseases (Gleason et al., 1991; Mitch, 1994, Stanley et al., 1997). Recent evidence has shown its clinical and pharmacological effects in anti-depressant and -viral medications. Such properties are attributed to the particular combination of the same hypericin (Gleason et 
al., 1991). H. perforatum can be found at high altitudes; and in Iran, it is scattered throughout the northern latitude. Due to climatic and environmental factors and interactions with phisiomorphologic-specific plants in Northern Iran, H. perforatum has biochemically adapted to the area, which has resulted in the formation of many important phenolic compounds such as hypericin (Zargari, 1996). H. perforatum is exposed to a high degree variation of genotypic and phenotypic, particularly among varied populations (Walker et al., 2001). For example, some researchers have reported that the qualitative variation between the two subspecies of Hypericum (H. perforatum ssp. and $H$. veronense ssp.) with small oval-egg leaves there are not hypericin and hyperforin (Couceiro et al., 2006). However, factors such as geographic location for growing the plant, harvest time, and at the second level of importance, the second metabolites production conditions are important (Filippini et al., 2010). In this respect, several studies were conducted in relation to the differences of hypericin (Campbell et al., 1997; Southwell et al., 1991; Jensen et al., 1995). The results showed that the amount of hypericin produced can change due to varying environmental conditions (Erken et al., 2001). Different possibilities of hypericin in genotypes should be considered on influencing factors: environment, genotype, or their interactions (Buter et al., 1998).

Currently, morphological, biochemical, and DNA markers are used to identify genetic diversity in plants. Molecular markers are preferred over other methods because they are infinite and do not depend on the growth period of the plant and environmental conditions. Therefore, molecular markers are used extensively in studies on genetic diversity (Aas et al., 1994; Ghalachyan et al., 2014). Genetic diversity is necessary for plant breeding derived from natural evolution and is an important biological system component of sustainability (Rubatzky and Yamaguchi, 1997). Other advantages of genetic diversity include species conservation management, within-species genetic diversity knowledge, assessment danger of extinction, and evolutionary potential (Hedrick, 2001). RAPD markers are a widely used in the genetic evaluation because they use small amounts of DNA to identify variations between plants at the DNA level and do not require information of the genome of interest. RAPD applications in plant breeding consist genetic mapping, Marker Assisted Selection (MAS) and transfer of useful genes and germplasm evaluation (Boonparkob, 1996; Garcia et al., 2004). RAPD marker is based on DNA amplification by non-specific primers and uses the polymerase chain reaction. Advantages of this marker include simultaneous assessment of multiple loci in the genome samples, no probing, radioactive materials, the low cost, and also is the speed of application execution from a special position in the molecular evolution of genetic diversity (Williams et al., 1990). One disadvantage of the RAPD markers is the low reproducibility (Naghavi et al., 2005). In recent years, numerous studies using RAPD markers have been used to assess the genetic diversity of medicinal plant species such as Achillea fragrantissima (Morsy, 2007), Satureja hortensis L. (Hadian et al., 2008), Carthamus tinctorius L. (Maali Amiri et al., 2001), Ocimum gratissimum L. (Vieria et al., 2001), Ferula gummosa Boiss (Talebi Kohyakhy et al., 2008), and $H$. perforatum clones (Tonk et al., 2011).

Since the Hypericum perforatum L. as well as distributed in the region of Hyrcanian in Iran, but yet not been conducted to identify in plant varieties, until preparing superior cultivar to replicate cultures spread and utilization of medicinal. The aim of this research was to discover distant cultivars that can be used in an ongoing $H$. perforatum 
L. hybridization program and hypericin content in the Hyrcanian located in the Caspian climate north of Iran.

\section{Materials and Methods}

\section{Plants and Growth Conditions}

Plant materials of Hypericum perforatum L. were collected in September-October of 2014 from 3 provinces and 15 places (Table 1, Fig.1) in the north of Iran (Hyrcanian Province). Temperatures ranged from $20^{\circ} \mathrm{C}$ to $25^{\circ} \mathrm{C}$. Leaf samples were placed on ice, during transport to the laboratory of Islamic Azad University Tonekabon Branch (IAUTB). Reference specimens were placed in the (IAUTB) herbarium.

Table 1. The clone collected from different provinces in Hyrcanian

\begin{tabular}{|c|c|c|c|c|c|c|c|c|c|c|c|c|c|c|}
\hline 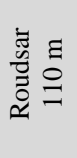 & 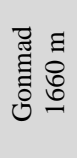 & 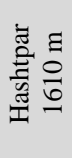 & 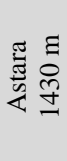 & 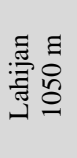 & 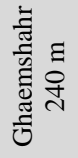 & 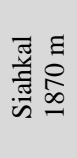 & 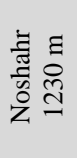 & 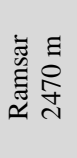 & 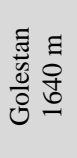 & 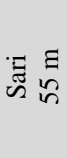 & 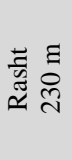 & 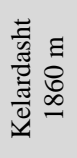 & 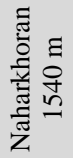 & 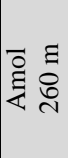 \\
\hline $\mathbf{P}_{57}$ & $\mathbf{P}_{53}$ & $\mathbf{P}_{49}$ & $\mathbf{P}_{45}$ & $\mathbf{P}_{41}$ & $\mathbf{P}_{37}$ & $\mathbf{P}_{33}$ & $P_{29}$ & $\mathbf{P}_{25}$ & $\mathbf{P}_{21}$ & $\mathbf{P}_{17}$ & $\mathbf{P}_{13}$ & $\mathbf{P}_{9}$ & $\mathbf{P}_{5}$ & $P_{1}$ \\
\hline
\end{tabular}

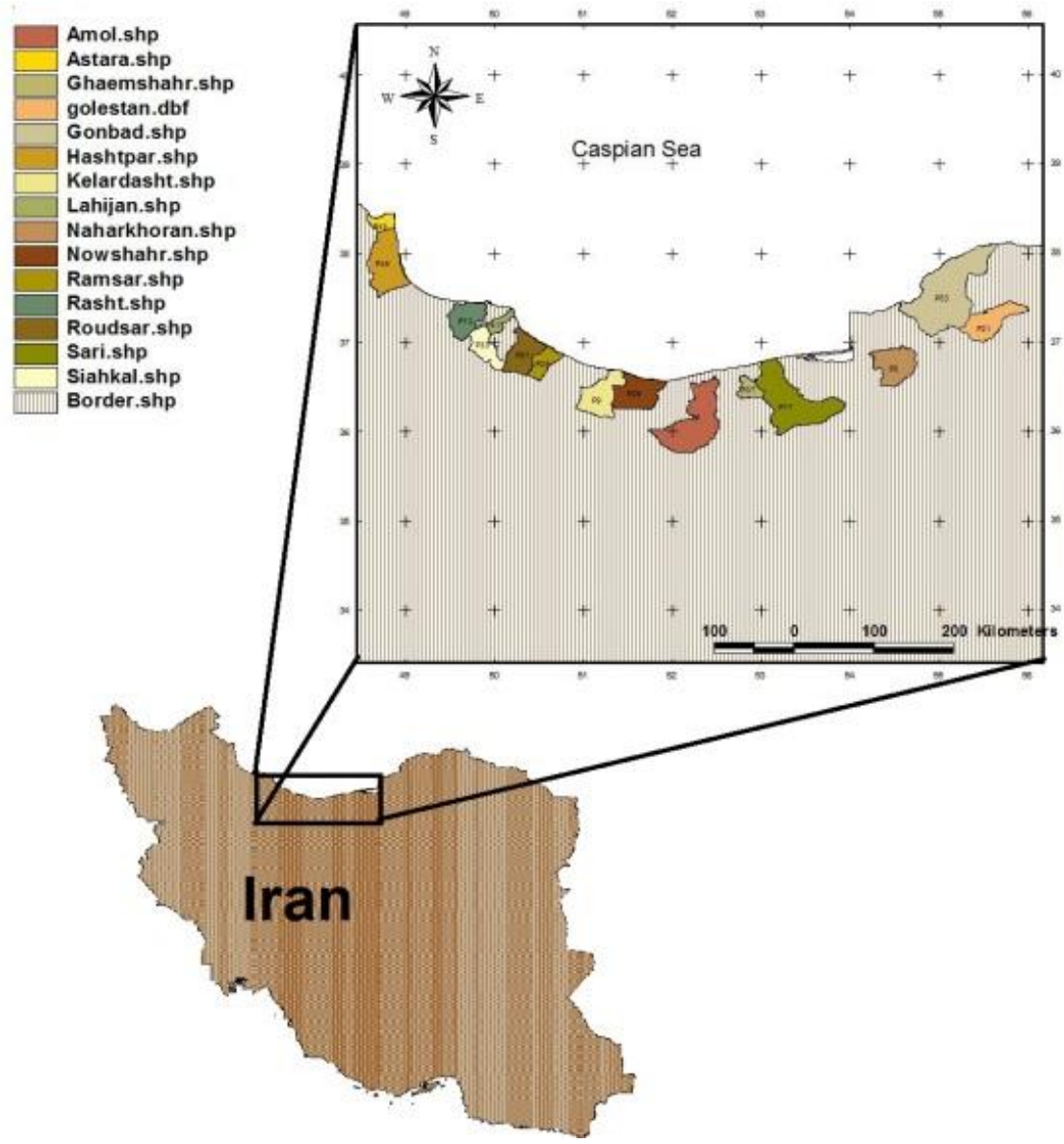

Figure 1. Hypericum perforatum L. sampling sites under Caspian climate 


\section{DNA Extraction and RAPD Analysis}

Fresh leaves from mature plants were frozen in liquid nitrogen and stored at $-80^{\circ} \mathrm{C}$. DNA was extracted using the method described by Khan et al. (2004). To decrease the effects of secondary metabolites in the process of extraction and to prevent DNA degradation as well as the subsequent inhibition of the polymerase chain reaction (PCR), we used a protocol described by Cheng et al., (2003). Co-precipitated RNA was separated, adding 0.5 units of RNAse per sample. The DNA extracted was dissolved in $\mathrm{TE}$ and for quality assessment, $12.5 \mathrm{ng} / \mu \mathrm{l}$ DNA in $\mathrm{ddH}_{2} \mathrm{O}$ was verified spectrophotometrically. Twenty-five primers that were 10 bases in length (GENEray biotechnology Co.) were chosen (Table 2). The selection of primers was made from a primer pool that gave strong and consistent amplification. PCR was performed using a thermal cycler (Bio RAD, MyCycler) and a reaction volume of $15 \mu 1$ that contained $4 \mu 1$ plant genomic DNA, $7.5 \mu 1$ ready-to-use master mix (Cinnagen Co., Tehran, Iran), $1 \mu \mathrm{l}$ primer (concentration of $0.5 \mathrm{mM}$ ), and $2.5 \mu \mathrm{l} \mathrm{ddH}_{2} \mathrm{O}$. The conditions used were as follows: one cycle for $5 \mathrm{~min}$ at $95^{\circ} \mathrm{C}$ and 40 cycles of $1 \mathrm{~min}$ at $94^{\circ} \mathrm{C}, 2 \mathrm{~min}$ at $34^{\circ} \mathrm{C}$, and $2 \mathrm{~min}$ at $72^{\circ} \mathrm{C}$. Cycling was finished with a final extension for $10 \mathrm{~min}$ at $72^{\circ} \mathrm{C}$. The PCR amplification products were separated via electrophoresis using $1.5 \%$ agarose gels. The DNA was stained with ethidium bromide and photographed under UV light in a gel documentation system (UVIdoc, UK).

Table 2. RAPD analysis with 15 Primers

\begin{tabular}{|c|c|c|c|c|c|c|c|}
\hline No. & Primers & $\begin{array}{c}\text { Primer }\left(3^{\prime}-5^{\prime}\right) \\
\text { sequence } \\
\text { RAPD }\end{array}$ & $\begin{array}{c}\text { Amplified } \\
\text { bands per } \\
\text { primer }\end{array}$ & Polymorphic & $\begin{array}{c}\text { Polymorphism } \\
\%\end{array}$ & PIC* & $\operatorname{Tm}\left({ }^{\circ} \mathrm{C}\right)^{*}$ \\
\hline 1 & OPAA10 & TGGTCGGGTG & 11 & 11 & 100 & .39 & 31.52 \\
\hline 2 & OPAD10 & AAGAGGCCAG & 13 & 13 & 100 & .41 & 24.24 \\
\hline 3 & OPM10 & TCTGGCGCAC & 8 & 7 & 88 & .35 & 32.77 \\
\hline 4 & OPV10 & GGACCTGCTG & 7 & 5 & 71 & .31 & 24.51 \\
\hline 5 & OPZ10 & CCGACAAACC & 8 & 8 & 100 & .40 & 25.75 \\
\hline 6 & $\mathrm{~B} 12 *$ & CCTTGACGCA & 5 & 1 & 20 & .12 & 27.94 \\
\hline 7 & E09* & CTTCACCCGA & 5 & 2 & 40 & .18 & 25.95 \\
\hline 8 & A04* & AATCGGGCTG & 4 & 1 & 25 & .14 & 30.91 \\
\hline 9 & $\mathrm{~A} 07 *$ & GAAACGGGTG & 6 & 2 & 33 & .21 & 25.75 \\
\hline 10 & OP-B12 & CCTTGACGCA & 8 & 7 & 88 & .36 & 27.94 \\
\hline 11 & OP-C11 & AAAGCTGCGG & 10 & 8 & 80 & .30 & 32.28 \\
\hline 12 & OP-C19 & GTTGCCAGCC & 8 & 7 & 88 & .34 & 30.93 \\
\hline 13 & OP-D20 & ACCCGGTCAC & 9 & 8 & 88 & .33 & 28.38 \\
\hline 14 & OP-Q11 & TCTCCGCAAC & 8 & 7 & 88 & .34 & 26.24 \\
\hline 15 & A12* & TCGGCGATAG & 5 & 1 & 20 & .11 & 28.17 \\
\hline & Mean & & 9 & 8.1 & 89.1 & .35 & 28.43 \\
\hline
\end{tabular}

*These primers were not entered in the analysis. *PIC: Polymorphism Information Content. *Tm: Temperature melting. 


\section{Data Analysis}

All the samples scored for the presence or absence of RAPD fragments with UVIsoft (version 12.6), and the data entered into a binary data matrix as discrete variables ("1" for the presence and " 0 " for the absence of a homologous band) with Excel (version 2003). Jaccard's coefficient of similarity calculated with Popgen software (ver. 1.44), and the species grouped by cluster analysis using based on Nei's unweighted pair-group of Arithmetic Means Averages (UPGMA) method and DICE Similarity coefficient with NTSYS Ver.2 Polymorphism Information Content for each primer combination was calculated from the formula $\mathrm{PIC}=1-\sum_{i=1}^{n} P{ }^{2}{ }^{2}$ ( $P i$ : allele frequency, n: the number of bands) (Anderson et al., 1993).

\section{Hypericin Analysis}

To evaluate the effect of genetic variations on production Hypericin, Cuttings are taken from of the genotypes mentioned provinces $(5-8 \mathrm{~cm}$ length cuttings) were cultivated in grow bags (Depth of $50 \mathrm{~cm}$ and the area of square $0.5 \mathrm{~m}^{2}$ ) filled with homogenized soil (Table 3). Genotype samples were cultivated in the geographic profile 39 S 0483774, UTM 4074954 (Tonekabon) and 25 meters from the sea level was selected. This experiment was conducted to completely randomized design with three replications, hypericin measurement samples were taken from flowering branches. Hypericin percentage was determined by the method of the European Pharmacopoeia (2008). The concentration of hypericin was calculated and compared with hypericin standard (Roth).

Table 3. Soil Profile

\begin{tabular}{|c|c|c|c|c|c|c|c|c|c|c|c|c|c|}
\hline \multicolumn{14}{|c|}{ Soil-texture: 'Loamo } \\
\hline $\begin{array}{c}\mathrm{Fe}^{*} \\
(\mathrm{ppm}) \mathrm{a}\end{array}$ & $\begin{array}{c}\mathrm{Mn}^{*} \\
(\mathrm{ppm}) \mathrm{o}\end{array}$ & $\begin{array}{c}\mathrm{Cu}^{*} \\
(\mathrm{ppm}) \mathrm{a}\end{array}$ & \begin{tabular}{c|}
$\mathrm{Zn}^{*}$ \\
$(\mathrm{ppm}) \mathrm{a}$
\end{tabular} & $\begin{array}{l}\text { Sampling } \\
\text { depthemo }\end{array}$ & $\begin{array}{c}\text { E.c' } \\
(\mathrm{d} s / \mathrm{m}) \mathfrak{2}\end{array}$ & $\mathrm{pHo}$ & 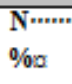 & $\begin{array}{l}\text { OM. } \\
\% \text { : }\end{array}$ & $\begin{array}{c}\text { P. } \\
\text { (ppm) } 2\end{array}$ & $\begin{array}{c}\mathbf{K}^{\cdot} \\
(\mathrm{ppm}) \mathrm{g}\end{array}$ & $\begin{array}{c}\text { Sand } \\
\%: 5\end{array}$ & $\begin{array}{l}\text { Silt" } \\
\%: 2\end{array}$ & $\begin{array}{c}\text { Clay: } \\
\% \therefore\end{array}$ \\
\hline 279 & 6.289 & $1.04=$ & .68 & $0-30=$ & .210 & $7.18 x$ & $6=$ & 33.39 & 42.179 & 1210 & 56.58 & 32.39 & 11.29 \\
\hline
\end{tabular}

\section{Results}

\section{DNA Analysis}

From the 15 RAPD primers used in this study, 10 primers were suitable and used in the analysis for all genotypes with a total of 90 different bands. Using a primer pool, 25 primers were identified as suitable for analysis and used to amplify a total of 90 different bands for all the genotypes. The mean number of bands for each primer was 9 bands. The number of polymorphic bands per primer ranged from 1 to 13 and the bands were 250 to 1000 bp in size (Fig. 2). The amplified bands are shown in Table 2. Based on the results, OPAD-10 primer with 13 bands and OPV-10 with 7 bands were the maximum and the minimum number of amplified bands, respectively. The lowest frequency among the polymorphic locus was 0.025 in the OPAD-10-2 and OPC-19-5 loci and OPAD-10-11 showed the highest frequency rate of 0.953. The mean of amplify frequency by RAPD primers are shown in Fig. 3. The value for each set of primers was the mean of amplification frequency of all loci related to the primer. 
Polymorphism information content (PIC) in the total population of 0.31 in primer OPV-10 to 0.41 for OPAD-10 was varied with the mean equal 0.35 for all primers (PIC $>0.1$ indicates heterozygosity). Nei's gene diversity $(\mathrm{H})$ is one of the important indicators in determining allele diversity. $\mathrm{H}$ values for each primer, which was obtained by averaging the $\mathrm{H}$ values, were calculated for each primer. The lowest $\mathrm{H}$ value (0.3011) was in the OPV-10 primer. The value of $\mathrm{H}$ estimated in each primer matches with the PIC, so that the primer OPAD-10 has the highest amount of PIC and equal to $\mathrm{H}$ (0.4001) (Table 1). Cluster analysis was performed using UPGMA and the Jaccard's similarity coefficient was calculated, with the highest correlation Cophenetic coefficient of 0.831 . The dendrogram (Fig. 4) obtained from the RAPD primers were sectioned at 0.67 similarity coefficient and the genotypes were grouped into four main groups: A, B, C, and D (Fig. 4).

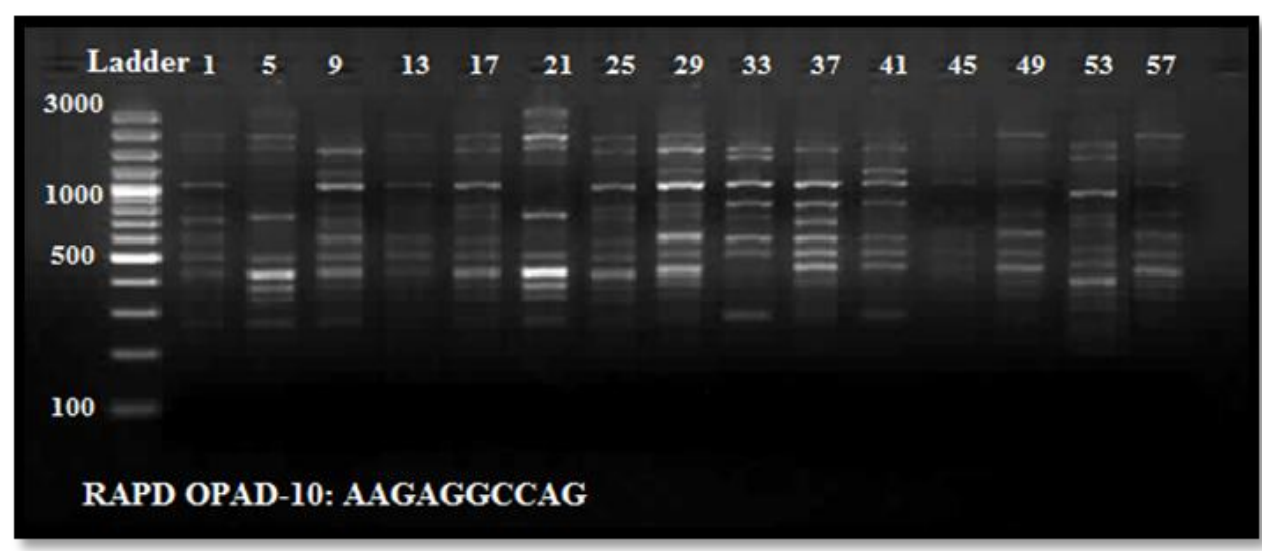

Figure 2. Banding pattern of amplified genomic DNA for Hypericum perforatum with using OPAD-10 RAPD primers.

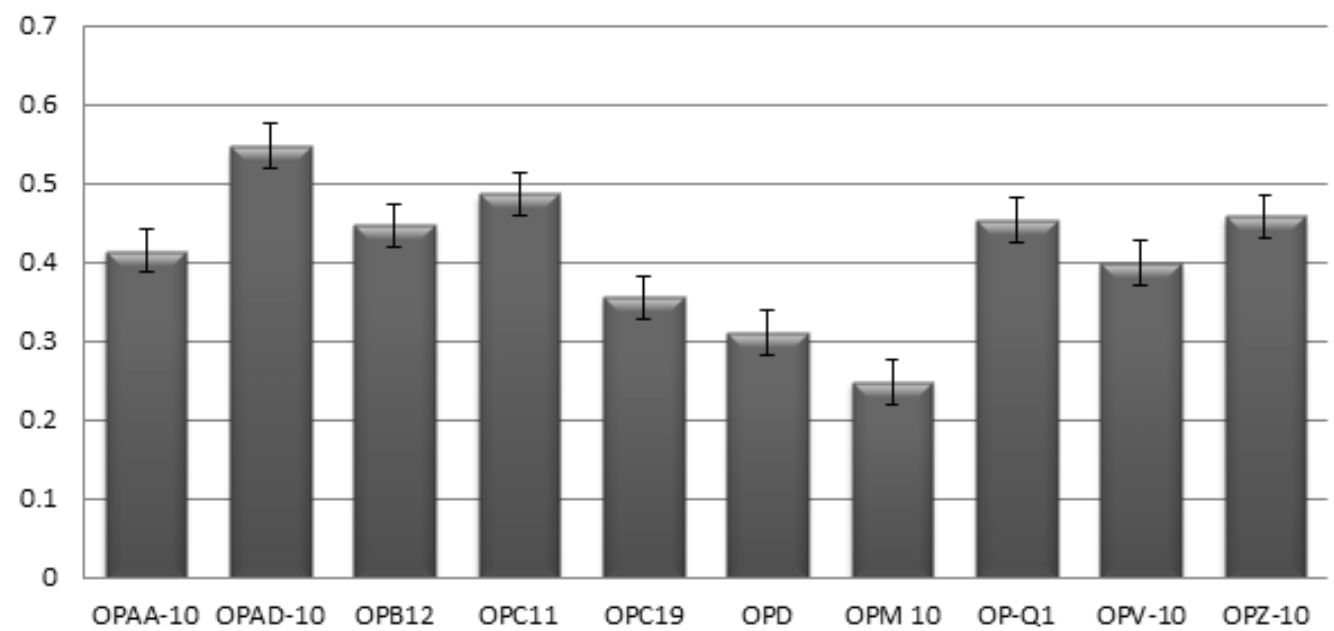

Figure 3. Mean of Amplify Frequency by RAPD Primers

The A group consisted of three subgroups, $\mathrm{A}_{1}, \mathrm{~A}_{2}$, and $\mathrm{A}_{3}$, and contained $40 \%$ of the genotypes. $\mathrm{A}_{1}$ consisted of $\mathrm{P}_{1}, \mathrm{P}_{13}$, and $\mathrm{P}_{17}$ genotypes. It was separated from the other 
two subgroups by a similarity coefficient of $76 \%$. In this subgroup, $\mathrm{P}_{1}$ and $\mathrm{P}_{13}$ genotypes have a greater affinity towards each other. $\mathrm{A}_{2}$ had a similarity coefficient of $72 \%$ with genotype $\mathrm{P}_{25}$, which is separated from $\mathrm{A}_{3}$. $\mathrm{A}_{3}$ had a similarity coefficient of $75 \%$ with genotypes $\mathrm{P}_{9}$ and $\mathrm{P}_{29}$. The $\mathrm{B}$ group contained two subgroups, $\mathrm{B}_{1}$ and $\mathrm{B} 2$. This constituted about $40 \%$ of genotypes with $69 \%$ similarity coefficient. 'The $\mathrm{B}_{1}$ subgroup contained $\mathrm{P}_{33}, \mathrm{P}_{37}$, and $\mathrm{P}_{41}$ genotypes. $\mathrm{P}_{37}$ and $\mathrm{P} 41$ genotypes were the most similar to one another. The $\mathrm{B}_{2}$ subgroup included $\mathrm{P}_{45}, \mathrm{P}_{49}$, and $\mathrm{P}_{57}$ genotypes. $\mathrm{P}_{49}$ and $\mathrm{P}_{57}$ genotypes were very similar to each other. The third group $\mathrm{C}$ contained $6.7 \%$ of the genotypes and had a similarity coefficient of $62 \% . \mathrm{P}_{53}$ was placed in this cluster. The fourth group (D) contained $13.3 \%$ of the genotypes and had a similarity coefficient of 76\%. $\mathrm{P}_{5}$ and $\mathrm{P}_{21}$ genotypes were part of this group. According to the dendrogram, the genotypes were separated into groups and subgroups. As a result, it becomes clear, cluster analysis confirmed that the analysis of molecular similarity and genetic distance (calculated by the software is POPGENE).

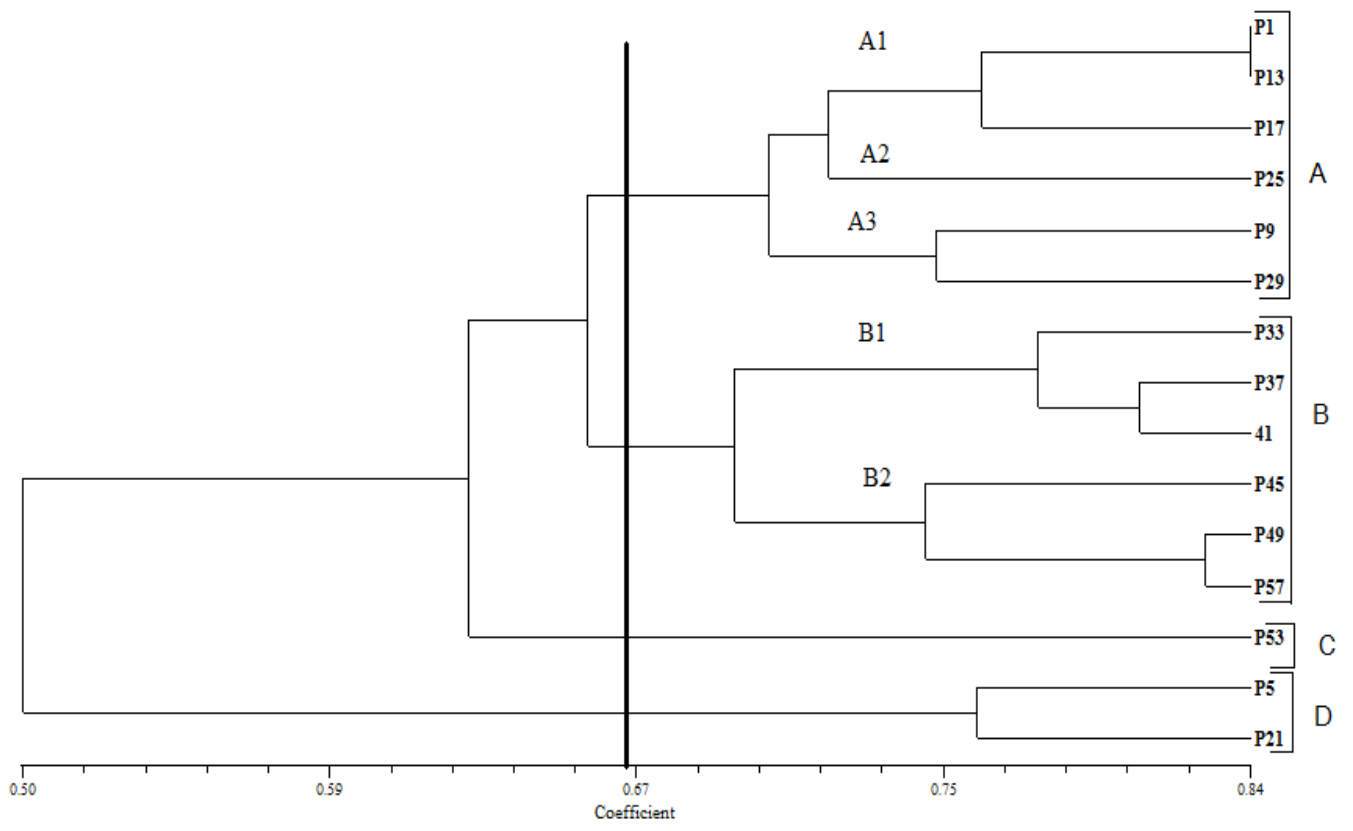

Figure 4. Dendrogram obtained by cluster analysis based on the presencelabsence matrix. The numbers on the left side correspond to different genotypes.

Arrangements of the 15 cumulative population using genetic similarities based on the RAPD primers are shown in Fig. 5. This figure shows that the principle coordinates analysis and the drawn two-dimensional plots are similar to the cluster analysis results. The aggregation of Hypericum genotypes in one area of the two-dimensional plot indicates that these genotypes are genetically similar. In this study, the maximum similarity was observed between regions $\mathrm{P}_{1}$ and $\mathrm{P}_{13}$. Since these two populations of morphological traits are different, i.e., leaf length and width, the distance between the upper and lower leaf and black leaf glands are similar, but in terms of the growth area. In this regard, there may be several factors, including the movement of seed in these two regions or do not cover of the primer (due to the inadequacy of the number and function) for the entire genome. In other populations, the highest similarity was 
observed between populations $\mathrm{P}_{49}-\mathrm{P}_{57}, \mathrm{P}_{41}-\mathrm{P}_{37}$ and $\mathrm{P}_{5}-\mathrm{P}_{21}$. According to the genetic similarity in different climates, we can conclude that molecular diversity was not associated with geographical distribution.

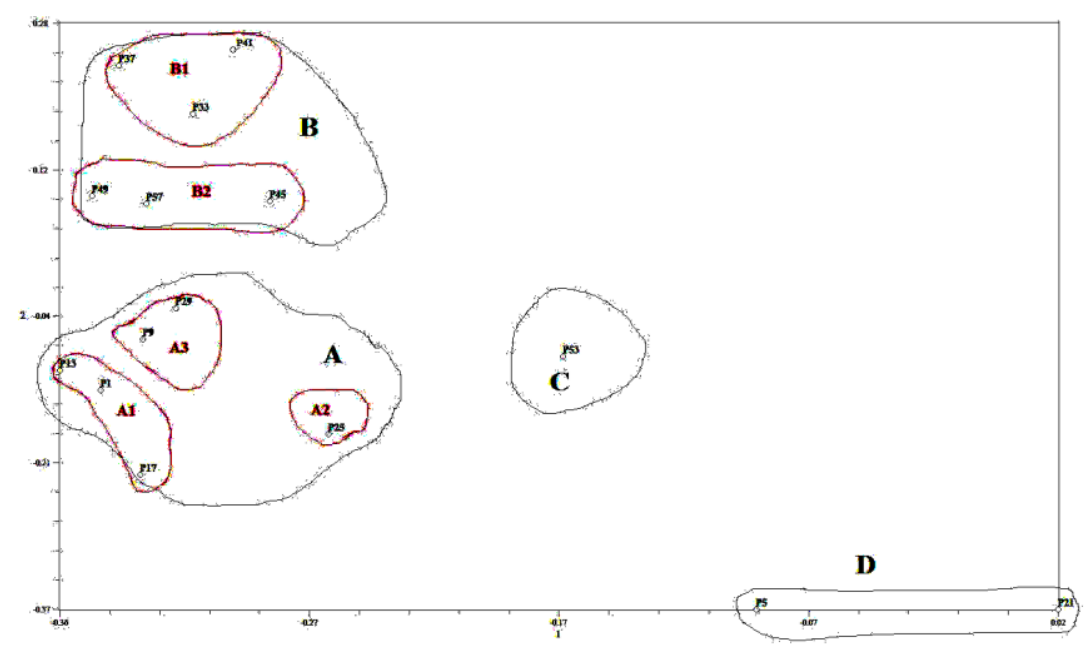

Figure 5. The two-dimensional scatter plot of the principal coordinates analysis RAPD primers.

\section{Hypericin Measurement}

Hypericin changes were very significant in genotypes grown under identical conditions. The highest amount of hypericin was measured in the Kalardasht genotype and the lowest amount in Roodsar and Noshahr genotypes (Fig. 6). Therefore, these changes in hypericin are related to the genotypes and not to the environmental conditions. Although the production of hypericin changes under ambient conditions, for determining superior genotypes, gives the best results from the comparison of the results genotypes cultivated under identical conditions with molecular analysis.

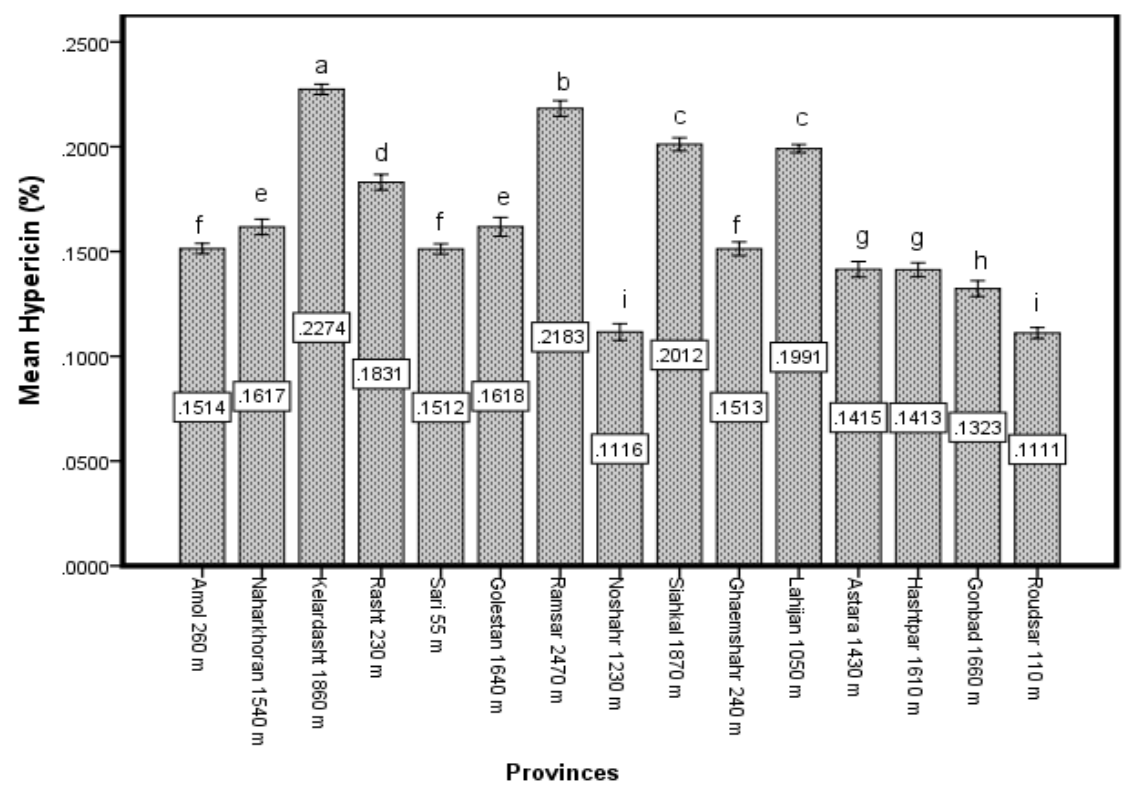

Figure 6. Hypericin levels in different Provinces 


\section{Discussion}

It is best to use primers that are distributed evenly throughout the genome in order to sample the entire genome, so if the markers are selected from different parts of the genome will be low between correlations. As a result, the principal coordinates analysis, a greater number of components required for variations justification in the data. Several factors affect the estimation of genetic relationships between individuals including the number of markers used such as the distribution of markers in the genome and nature's evolutionary mechanisms. Plant genetic diversity is impacted by anthropogenic climate change and its effects. Therefore, the search for gene banks containing new genotypes is required for the future of agriculture and the development of resistant plants. Hypericum has a high degree of phenotypic and genotypic changes. In this regard, several studies have compared the properties of Hypericum from California, Oregon, and Montana. Several regional differences were observed in chemical properties (i.e., hypericin content) and morphology (i.e., gland density, leaf area, stems length and ratio of leaf length to width) (Walker et al., 2000, 2001). It is worth mentioning that Hypericum is exposed to changes in the morphological and genetic variation and it's the response of the plant to deal with herbivores (Buckley et al., 2003). The results of the genetic screening in this study showed that there are genotypic differences between $H$. perforatum grown in different regions of Hyrcanian. This is in agreement with the results reported by Tonk et al. (2011). Our research revealed that genotypes and environmental factors can affect the efficiency of secondary metabolite production. These factors can significantly increase the concentration of hypericin in $H$. perforatum in various provinces in Iran and at different altitudes. Based on the results obtained, the best altitude for growing, genotype, location for growth, and ecotype was determined in this study.

Acknowledgments. This work had financially supported by the research council of Islamic Azad University, Tonekabon Branch, Tonekabon, Iran.

\section{REFERENCES}

[1] Aas, G., Maier, J., Baltisberger, M., Matzger, S.(1994): Morpholgy, isozyme variation, cytology, and reproduction of hybrids between Sorbusaria (L) Crantz and S.torminalis (L). - Botanica Helvetica 104: 195-214.

[2] Anderson, J.A., Churchill, G.A., Autrique, J.E., Tanksley, S.D., Sorrells, M.E.(1993): Optimizing parental selection for genetic linkage maps. - Genome 36:181.

[3] Azizi, M., Omidbaigi, R.(2002): Effect of NP supply on herb yield, hypericin content and cadmium accumulation of St.John's wort (Hypericum perforatum L.). - Acta Horticulture 576: 267-271.

[4] Bais, H.P., Vepachedu, R., Lawrence, C.B., Stermitz, F.R., Vivanco, J.M .(2003): Molecular and biochemical characterization of an enzyme responsible for the formation of hypericin in St. John's wort (Hypericum perforatum L.). - Journal of Biological Chemistry 278: 32413-32422.

[5] Boonparkob, U.(1996): RAPD Polymorphism in Diploid Plums: Genetic Relationships and Genetic Linkage Maps. - Texas A and M University, p.256.

[6] Buckley, Y.M., Briese, D.T., Rees, M.(2003): Demography and management of the invasive plant species Hypericum perforatum L. Using multi-level mixed-effects models 
for characterizing growth, survival, and fecundity in a long-term data set. - Journal of Applied Ecology 40: 481-493.

[7] Buter, B. C., Orlacchio, A., Soidati, B. and Berger, K .(1998): Significance of genetic and environmental aspects of the field cultivation of Hypericum perforatum L. - Planta Medica 64:431-437.

[8] Campbell, M. H., May, C. E., Southwell, L. A., Tomlinson, J. D., Michael, P. W. (1997): Variation in Hypericum perforatum L. (St. John's wort) in New South Wales. - Plant Protection 12: 64-66.

[9] Cheng Y.J., Guo W.W., Yi H.L., Pang X.M., Deng X. (2003): An efficient protocol for genomic DNA extraction from citrus species. - Plant Molecular Biology Report 21: $177 \mathrm{a}-177 \mathrm{~g}$.

[10] Couceiro; M.A., Afreen, F., Zobayed, S.M.A., Kozai, T.(2006): Variation in concentrations of major bioactive compounds of St. John's wort, Effects of harvesting time, temperature and germplasm. - Plant Science 170: 128-134.

[11] Erken, S., Malyer, H., Demirci, F., Demirci, B., Baser, K.H.C.(2001): Chemical investigations on some Hypericum species growing in Turkey I.- Chemistry of Natural Compounds 37: 434-438.

[12] European Pharmacopoeia (2008): St. John's wort. In European Pharmacopoeia. $6^{\text {th }}$ edn. Council of Europe, Strasbourg, France, pp.2958-2959.

[13] Fars, M., Zolali, J.(2004): Principle of Plant biotechnology. - Ferdosi Mashhad University Press, p.495.

[14] Filippini, R., Piovan, A., Borsarini, A., Caniato, R.(2010): Study of dynamic accumulation of secondary metabolites in three subspecies of Hypericum perforatum. Fitoterapia 81: 115-119.

[15] Garcia, A. A. F., Benchimol, L. L., Barbosa, A. M. M., Geraldi, I.O., Souza, C.L. (2004): Comparison of RAPD, RFLP, AFLP, SSR marker for diversity studies in tropical maize inbred lines. - Genetics and molecular biology 27: 579 - 88 .

[16] Ghalachyan, L. M., Asatryan A. Z., Kocharyan K. A., Tadevosyan L.S. (2014): The accumulation of artificial radionuclides in spice herbs in different zones under the impact of the Armenian NPP. - Bulletin of State Agrarian University of Armenia 2: 17-20.

[17] Gleason, H. A., Cronquist, A. (1991): Manual of vascular plants of northeastern United States and adjacent Canada. 2nd ed. - New York: New York Botanical Garden, p. 910.

[18] Hadian, J., Tabatabaei, S. M. F., Naghavi, M.R.Z., Jamzad Ramak-Masoumi, T.(2008): Genetic diversity of Iranian accessions of Satureja hortensis L. based on horticulturaltraits and RAPD markers. - Scientia Horticulturae 115 (2): 196-202.

[19] Hedrick, P.W. (2001): Conservation genetics: where are we now? - Trends in Ecology and Evolution 16: 629-636.

[20] Jensen, K.I.N., Gaul, S.O., Specht, E.G., Doohan, D.J. (1995): Hypericin content of Nova Scotia biotypes of Hypericurn perforatum L. - Canadian Journal of Plant Science 75: 923-926.

[21] Khan, I.A., Awan, F.S., Ahmad, A., Khan, A.A .(2004): A modified mini-prep method for economical and rapid extraction of genomic DNA in plants. - Plant Molecular Biology Reporter 22: 89a-89e.

[22] Maali Amiri, R., Yazdi-Samadi, B., Ghanadha, M.R., Abd-Misiiani, C.(2001): Detection of DNA Polymorphism in Land race Populations of Safflower in Iran Using RAJPDPCRTechnique. - Iranian Journal of Agriculture science 32(4): 737-745.

[23] Mairapetyan, S., Mamikonyan, V., Alexanyan, J., Tovmasyan, A., Daryadar, M., Stepanian, B.(2016): Productivity, Biochemical Indices and Antioxidant Activity of Peppermint (Mentha Piperita L.) and Basil (Ocimum Basilicum L.) in Conditions of Hydroponics. - J Aquac Res Development 7(430): 2.

[24] Mitch, L.W.(1994): Interguing word of weed common St.Johns wort. - Weed Technology 8: 658-661. 
[25] Morsy; A.A.(2007): Molecular variations of Achillea fragrantissima (Forssk.) SCH.BIP. growing in five areas of south Sinai.- International Journal of Agriculture and Biology 9: 11-17.

[26] Naghavi, M., Ghareyazie, B., Hosseini Salekdeh, Gh. (2005): Molecular Markers. Tehran University Press.Tehran, Iran, p. 320.

[27] Omidbeigy, R.(2001). Production and processing of medicinal plants. Volume I. - Razavi Publications, p.364.

[28] Peterson, C., Coats, J.(2001): Insect repellents-Past, present, and future. - Pesticide Outlook 12(4):154-158.

[29] Rubatzky, V. E., Yamaguchi, M. (1997): World Vegetables: Principles, Production, and Nutritive Values. (2nd ed). - Chapman and Hall, NY. 704.

[30] Sirvent, T. M., Walker, L., Vance, N., Gibson, D. M. (2002): Variation in hypericins from wild populations of Hypericum perforatum L. in the Pacific Northwest of the U.S.A. Economic Botany 56(1): 41-48.

[31] Southwell, I.A., Campbell, M.H.(1991): Hypericin content variation in Hypericum perforatum in Australia. - Phytochem 30: 475-478.

[32] Stanley, J. D, Wipff, J. K., Montgomery, P. M. (1997): Vascular plants of Texas. Austin, TX: University of Texas Press, p.404.

[33] Talebi Kohyakhy, E., Mohammad Aliha, M., Naghavi, M.R. (2008): Genetic diversity inFerula gummosa Boiss. populations of Iran using RAPD molecular markers. - Iranian Journal of Medicinal and Aromatic Plants 23(4): 514-522.

[34] Tonk, F.A., Giachino, C., Sonmez, S., Yuce, E., Bayram, İ., Furan M.A.(2011): Characterization of various Hypericum perforatum clones by hypericin and RAPD analyses. - Internationak Journal of Agricultureand Biology 13: 31-37.

[35] Vardanyan, A.P., Sargsyan, E. D. (2014): Studies on antiradical activity of hydroponic Hypericum Perforatum L. medicinal raw material. - Bulletin of National Agrarian University of Armenia 3(47): 37-40.

[36] Vieria, R.F., Grayer, R.J., Paton, A., Simon, J.E.(2001): Genetic diversity of Ocimum gratissimum L. based on volatile oil constituents, flavonoids and RAPD markers. Biochemical Systematics and Ecology 29(3): 287-304

[37] Walker, L., Sirvent, T., Gibson, D., Vance, N. (2001): Regional differences in hypericin and pseudohypericin concentrations and five morphological traits among Hypericum perforatum plants in the north western United States. - Canadian Journal of Botany 79: 1248-1255.

[38] Walker, L.W.(2000): St. John's wort (Hypericum perforatum L. Clusiaceae): biochemical, morphological, and genetic variation within and among wild populations of the northwestern United States. - Portland, OR: Portland State University, p.162. Thesis.

[39] Weed, K.(2000): St. John's wort. - Purdue University Vet http://www.vet. Purdue. edu/depts./addl/toxic/plant 38.htm.

[40] Williams, J.G.K., Kubelik, A.E., Livak, K.J., Rafaiski, J.A., Tingey, S.V.(1990): DNA polymorphisms amplified by arbitrary primers are useful as genetic markers. - Nucleic Acid Research 18(22): 6531-6536.

[41] Zargari, A.(1996): Medicinal plants. Volume II. - Tehran University Publications, p.550. 